que a doutrina brasileira começou a se preocupar com o tema. Já ali constavam diversas referências às idéias e à obra de Mauro Cappelletti, cuja influência é confirmada por Ada Pellegrini Grinover $^{21}$, autora juntamente com Cândido Rangel Dinamarco, Kazuo Watanabe e Waldemar Mariz de Oliveira Jr. do anteprojeto da Lei.

Não por acaso, três processualistas ilustres, autores, juntamente com outros juristas, do anteprojeto que resultou no Código Brasileiro de Defesa do Consumidor (Lei n ${ }^{\circ} 8.078$, de 11 de setembro de 1990), Ada Pellegrini Grinover, Kazuo Watanabe e Nelson Nery Júnior, têm grande intimidade com a obra de Mauro Cappelletti, sendo clara a influência deste em várias regulações desse verdadeiro monumento legislativo. Nos seus comentários ao Código prestam eles o devido reconhecimento, principalmente no que concerne às ações coletivas ali estatuídas ${ }^{22}$. Diz Ada Pellegrini Grinover, com expressa menção à obra de Cappelletti, que justamente por se tratar de defesa dos direitos do consumidor, a preocupação do legislador nesse passo é com a efetividade dessa proteção e com a facilitação de seu acesso à justiça ${ }^{23}$. Assim também Kazuo Watanabe ao ressaltar, citando também Cappelletti, a manifesta intenção do legislador brasileiro de incrementar a instrumentalidade substancial e a maior efetividade do processo e adequá-lo à nova realidade socioeconômica que estamos vivendo, marcada profundamente pela economia de massa ${ }^{24}$
4. Qualquer reflexão moderna sobre o processo há de levar em conta suas conexões internas e externas. Não basta tão somente o estudo da técnica, simples meio para atingir-se determinado resultado, porquanto o processo como fenômeno cultural se conforma em razão dos valores imperantes em determinada sociedade, das suas idéias, utopias, estratégias de poder, fatores sociais, econômicos e políticos Portanto, sempre se revela necessário atentar aos liames com a realidade social externa: a mais grave miopia de que pode padecer o processualista é ver o processo como medida de todas as coisas. Nenhuma tentativa de controlar o arbítrio estatal e de forma concomitante estabelecer padrões que permitam ao processo alcançar suas finalidades últimas em tempo razoável e ainda colaborar para a justiça do provimento judicial poderá frutificar, se não se atentar às vertentes políticas, culturais e axiológicas dos fatores condicionantes e determinantes de sua estruturação e organização ${ }^{25}$.

Mauro Cappelletti foi o grande inspirador e paladino em nossa época dessa ótica mais humana e realista de sentir e pensar o fenômeno processual. Sua visão sociológica do processo, herdada de Piero Calamandrei, a vivência compartilhada do civil law e do common law, a aptidão de seu refinado espírito para as vicissitudes da pós-modernidade, fizeram com que se tornasse um observador privilegiado dos grandes conflitos de valor do século XX e principalmente um renovador insuperável dos estudos do direito processual.

${ }^{21}$ Cf. Novas tendências na Tutela Jurisdicional dos Interesses Difusos, in O Processo em sua Unidade - II, Rio de Janeiro, Forense, 1984, p. 88-121. Como é aí informado, p. 116, o anteprojeto foi, inicialmente, apresentado no I Congresso Nacional de Direito Processual, realizado em Porto Alegre, de 11 a 16 de julho de 1983 , onde fo cões sobre o tema, sugerindo, além de modificaç̃os formais, a previsão do controle da medida liminar nas acões civis inibitórias. Após as manifestações favoráveis dos Professores Galeno Lacerda, Calmon de Passos e Ovídio Baptista da Silva, foi aprovado por aclamação.

${ }^{22}$ Ver Ada Pellegrini Grinover et allia, Código Brasileiro de Defesa do Consumidor Comentado pelos Autores do Anteprojeto, $6^{\mathrm{a}}$. ed., Rio de Janeiro, Forense Universitária, 1999, passim.

${ }^{23}$ Ada Pellegrini Grinover, Código Comentado, cit., p. 701.

${ }^{24}$ Kazuo Watanabe, Código Comentado, cit., p. 706.

${ }^{25}$ Maior desenvolvimento dessas idéias em Carlos Alberto Alvaro de Oliveira, Do Formalismo no Processo Civil São Paulo, Saraiva, 1997, passim.

\title{
Desembargador Carlos Thompson Flores: fundador da Faculdade de Direito de Porto Alegre
}

\author{
Dr. Carlos Eduardo Thompson Flores Lenz \\ Desembargador Federal do Tribunal Regional Federal da $4{ }^{a}$ Região
} Salão Nobre da Faculdade de Direito da Universidade Federal do Rio Grande do Sul, a propósito das Comemorações do Centenário da fundação daquela Faculdade de Direito.

É para mim honra inexcedível comparecer a esta Faculdade de Direito com o objetivo de proferir palestra sobre a vida e a obra do Desembargador CARLOS THOMPSON FLO RES, Fundador e primeiro Diretor da Faculdade de Direito de Porto Alegre, hoje integrante da Universidade Federal do Rio Grande do Sul.

Atendo, pois, com emoção, à honra do convite que recebi dos eminentes professores EDUARDO CARRION e PLINIO DE OLIVEIRA CORRÊA, respectivamente, Diretor e ViceDiretor da Faculdade de Direito, para colaborar nas comemorações do centenário da fundação desta notável instituição de ensino jurídico. Cuidarei de não desmerecê-lo, neste momento, não somente pela nobreza da missão recebida, como pela validade de seu significado no mundo emocional em que se insere o pretexto altíssimo desta comemoração. A todos, o meu agradecimento pela oportunidade que me deram de exaltar a memória de seu fundador, personalidade de grande relevo na história da Política e da Magistratura do nosso Estado no Império e primórdios da República.
O nome do Desembargador CARLOS THOMPSON FLORES foi pronunciado, reverentemente, vezes incontáveis, sob as variadas facetas de sua impressionante e encantadora personalidade, como atestam os seus contemporâneos, por ocasião das comemorações de sucessivas datas significativas da vida desta Casa do Direito. Os ecos de tantos louvores ainda persistem. Hoje mesmo, a Faculdade de Direito de Porto Alegre lhe dedicou um dia de reverência, à memória daquele que foi o seu principal fundador e primeiro Diretor.

Não será por demais repetir e enaltecer o descortino da geração da Independência do Brasil ao perceber que a novel Nação não necessitava unicamente de novas leis, mas, sobretudo, de uma consciência jurídica própria, a qual somente poderia se concretizar com a fundação de Faculdades de Direito vinculadas às nossas tradições.

A respeito, precioso o depoimento de CLOVIS BEVILAQUA, em sua consagrada História da Faculdade de Direito do Recife, verbis:

"Remontam aos tempos coloniais as aspirações brasileiras por possuírem, dentro do país, estabelecimentos de ensino superior, onde pudessem desenvolver as suas faculdades naturais, em harmonia com a cultura do tempo. Os 
inconfidentes mineiros, no fim do século décimo oitavo cogitaram de dotar a pátria livre com uma Universidade." 1

A necessidade, então geralmente sentida, de se criarem no Brasil Faculdades de Direito teve o seu arauto na pessoa de JOSÉ FELICIANO FERNANDES PINHEIRO, o Visconde de São Leopoldo, consoante se constata do discurso que proferiu quando da sessão de 14 de junho da Constituinte de 1823, oportunidade em que afirmou o eminente homem público brasileiro, verbis

"Proponho que, no Império do Brasil se crie, quanto antes, uma universidade pelo menos, para assento da qual parece dever se preferida a cidade de $S$. paulo, pelas vantagens naturais, e razões de conveniência geral. Que, na faculdade de Direito civil, que será sem dúvida, uma das que comporá a nova universidade, em vez de multiplicadas cadeiras de Direito romano, se substituam duas, uma de Direito público constitucional, outra de economia política." 2

Com a posterior dissolução da Assem bléia Constituinte pelo Imperador Dom Pedro I restaram inúteis os seus esforços em prol das Faculdades de Direito, o que somente veio a efetivar-se quando a Assembléia Geral votou Pedro I sancionou a Carta de Lei de 11 de agosto de 1827 , o diploma criador das Faculdades Jurídicas do Brasil.

Surgiram, assim, logo em 1827, os dois grandes centros jurídicos do País: um ao norte, em Olinda, posteriormente transferido para $\mathrm{Re}-$ cife; outro, em São Paulo. Ambos iriam se converter nos dois pólos em torno dos quais, no decorrer de várias décadas, a intelectualidade

brasileira pôde traçar a elipse da nossa cultura.

Instalava-se, portanto, em nossa incipiente Nação o culto ao Direito, que tão profundamente marcara a civilização romana, conforme magistralmente expõe RUDOLF VON JHERING, em obra clássica, verbis:

"On connaît suffisamment l'inclination qu'eurent de tous temps les Romains pour le droit, bien différents en cela du peuple grec, et la place éminente qu'il occupait dans leur vie. Le droit et l'État étaient pour les Romains ce que furent la religion pour le peuple hébreu, l'art pour le peuple grec: un objet d'orgueil national vis-à-vis de tous les peuples étrangers, la supériorité dont ils étaient le plus certains, l'aimant de l'ambition et de la force. (...) L'attraction qu'exerçait le droit sur les Romains ne provenait pas de la satisfaction $q u$ 'il procurait à l'intelligence et au sens juridique. Le droit était pour eux plus qu'une simple source de jouissances et de satisfactions intellectuelles, il était pour eux un objet d'ennoblissement moral. (...) Ce respect du droit, la soumission spontanée du Romain aux dispositions du droit, l'amour du peuple pour la justice, son aversion pour les violations $d u$ droit, le sentiment de sécurité que le droit inspirait à Rome, la confiance en son triomphe, en un mot, le sentiment sain, énergique et viril de la légalité, voilà ce qui exaltait l'orgueil du Romain." ${ }^{3}$

Nesse contexto insere-se o nosso homenageado, CARLOS THOMPSON FLORES, bem como o ambiente político e cultural que originou a Faculdade Livre de Direito de Porto Alegre, fundada a 10 de fevereiro de 1900, durante o Governo de BORGES DE MEDEIROS, sendo instalada a 03 de maio do mesmo ano, no

${ }^{1}$ In História da Faculdade de Direito do Recife, $2^{\mathrm{a}}$ ed., Instituto Nacional do Livro, 1977, p. 11. 2 In Anais do Parlamento Brasileiro, Assembléia Constituinte, II, p. 63.

${ }^{3}$ In L'Esprit Du Droit Romain, tradução de O. de Meulenaere, $3^{\mathrm{a}}$ ed., Forni Editore, Bologna, t. I, pp. 324/5.

Revista da Faculdade de Direito da UFRGS, v. 20, Outubro/2001 prédio da Escola Normal do Estado, tendo como o seu primeiro Diretor o Desembargador CARLOS THOMPSONFLORES.

Foi esta a sétima Faculdade de Direito a ser implantada no País. Dessas, duas eram oficiais, como as de Recife e São Paulo. As quatro outras eram livres, localizadas duas no Rio de Janeiro, uma na Bahia e outra em Minas Gerais.

As Faculdades Livres, à época, eram autônomas e desvinculadas da tutela oficial, sendo constituídas por meio de associação de professores e patrimônio determinado, presente, portanto, a inspiração positivista de AUGUSTO COMTE que prega a criação dos estabelecimentos de ensino livres, "independentes da vexatória tutela oficial, fora da es tufa de subvenções orçamentárias que, além de ilegítimas, são humilhantes".

Em conferência que proferiu na Faculdade de Filosofia da Universidade Federal do Rio Grande do Sul, intitulada "O Direito no Rio Grande do Sul", o saudoso Professor SALGADO MARTINS registrou a importância da fundação da Faculdade de Direito de Porto Alegre para o desenvolvimento dos estudos jurídicos em nosso Estado, verbis:

"Além da instauração do novo regime, com todas as consequências e implicações no campo do direito positivo, deve ser apontada outra causa de grande influência do fomento desses estudos: a fundação da Faculdade Livre de Direito de Porto Alegre, no dia 17 de fevereiro de 1900 . No di em que for escrita a memória da primeira Faculdade rio-grandense de Direito, há de ser salientado o papel que lhe coube não só no aprimoramento da cultura jurídica como na penetração dessa cultura em áreas sociais até então inteiramente alheias a esse interesse, e ainda no preparo das nossas melhores elites dirigentes, a partir da República. Para se compreeender sob que signos e influências culturais se iniciou o ensino e o estudo sistematizado do Direito, no Rio Grande do Sul, é necessário atentar para São Paulo e Recife, onde se situavam os dois grandes centros de cultura jurídica e dos quais provinham os jovens rio-grandenses que se consagraram à fundação da República, no Rio Grande do Sul. E não só os jovens, mas também os mestres, eram filhos espirituais de uma ou outra Academia......)

Ora, as matrizes próximas da cultura jurídica rio-grandense estão, sem dúvida, nesssas, duas nobres e ilustres Academias.

THOMPSON FLORES, PLÍNIO DE CASTRO CASADO, JAMES DARCY, PLÍNIO ALVIM, LEONARDO MACEDÔNIA FRANCO E SOUZA, NORMÉLIO ROSA, JOAQUIM RIBEIRO, PACHECO PRATES, naturais do Rio Grande do Sul, vinham de São Paulo.

ANDRÉ DA ROCHA, MELCKISEDECK CARDOSO, RIBEIRO DANTAS, VALENTIM DO MONTE, filhos de Estados do Norte, haviam se diplomado na Faculdade de Recife e traziam no espírito e no coração a presença dominadora de TOBIAS BARRETO.

Dentro dessas coordenadas derivadas do meio, do passado histórico, das circunstâncias politicas e sociais, dos fatores culturais a que vimos aludindo, começa a se constituir, no Rio Grande do Sul, a literatura jurídica, exprimindo, ainda que de modo incipiente, o trabalho de elaboração doutrinária, de determinação dos principios fundamentais, ou de simples exegese das leis." 4

${ }^{4}$ In JOSÉ SALGADO MARTINS, O Direito no Rio Grande do Sul, conferência publicada pela Gráfica da Universidade Federal do Rio Grande do Sul, Porto Alegre, 1961. 
O Desembargador CARLOS THOMPSON FLORES descendia de antiga e ilustre família do Rio Grande do Sul que, segundo reza a tradição, originou-se do casamento do Dr. LUIZDA SILVA FLORES, médico humanitário e prestigioso político do Império, com Dona MARIA DA GLÓRIA THOMPSON, filha do Capitão de Fragata da esquadra inglesa JAYME THOMPSON. ${ }^{5}$

Nascido em Porto Alegre, a 04 de junho de 1843, estudou os preparatórios nesta Capital, cursando a Faculdade de Direito de São Paulo, onde colou grau a 27 de novembro de 1865. Depois de formado, retornou à Província, onde ocupou os cargos de Promotor Público, Juiz de Direito, Deputado Provincial, de 1871 a 1876, tendo exercido a Presidência da Assembléia Legislativa, e Presidente da Província do Rio Grande do Sul na situação liberal de 1878 a 1885. Com o advento da República, fo Desembargador do Superior Tribunal de Justiça do Estado, onde foi eleito por seus pares Vice-Presidente da Corte, estando no exercício da Presidência por várias oportunidades, Procurador-Geral do Estado e Deputado Estadual à Constituinte de 1891, onde teve destacada atuação. Paralelamente, desenvolveu intensa atividade como jornalista, colaborando ativamente na "Reforma".

Por ocasião do seu falecimento, era Desembargador do Superior Tribunal de Justiça, no exercício do cargo de Procurador-Geral do Estado, Catedrático da cadeira de Legislação Comparada de Direito Privado, que inaugurou e regeu durante o ano letivo de 1904, e Diretor da Faculdade de Direito de Porto Alegre.

O Desembargador THOMPSON FLORES foi casado com D. LUÍSA ELVIRA FERNANDES DOS REIS, filha do Marechal de Campo SALUSTIANO JERONIMO DOS REIS, o Barão de Camaquam, destacado militar do Império brasileiro.

LA BRUYÈRE, conhecido moralista francês, afirmou, com inteiro acerto, que não se deve julgar os homens como um quadro, ou uma figura, através de uma única e primeira vista: há uma intimidade e uma alma que é preciso aprofundar. $^{6}$

Magistrado por cerca de quarenta anos, CARLOS THOMPSON FLORES honrou a toga e deu-lhe majestade e o brilho que não era difícil vaticinar.

A marca de sua personalidade ímpar ele a deixa estampada na memória dos que o viram à frente das mais importantes funções nos três Poderes do Estado, no Império e na República, sendo notado pelos traços característicos de sua enorme e atraente personalidade - a inteligência vivacíssima, que se revelava nas conversas e debates, pelo raciocínio extraordinário, rápido, sutil e cintilante, auxiliado por memória invejável, aliada a sólidos conhecimentos dos diferentes ramos do Direito, e a ampla cultura humanística.

Autêntico magistrado, dedicado como poucos ao cumprimento de sua apostolar missão, seguiu à risca os ensinamentos de D'AGUESSEAU, notável Juiz de França: "Pouvoir tout pour la justice, et ne pouvoir rien pour soi-même, c'est l'honorable mais pénible condition du magistrat".?
A sua preocupação com as questões do ensino já se manifestara quando de sua atuação como parlamentar na Assembléia Legislativa, no Império, conforme se observa março de 1873, verbis:

"Obedecendo à rigorosa obrigação de atender os votos, às aspirações da opinião pública, as conveniências morais e do progresso intelectual de meus comprovincianos, eu veme faltam as disposições naturais, (muitos não apoiados) servindo o soberano interesse da grande política - a educação popular - a que voto profundo amor, tratar do transcendente assunto da instruçâo pública, que reclama hoje mais do que nunca a nossa solicitude, os nos sos desvelos, que insta pela mais severa atenção". (Apoiados) ${ }^{8}$

Com a proclamação da República, foi escolhido Desembargador do Superior Tribunal de Justiça do Estado, cargo que exerceu com extraordinária competência até os seus últimos dias de vida.

Em razão de sua larga experiência na vida pública, notadamente por ter governado o Rio Grande do Sul, a sua palavra era sempre ouvida com o maior acatamento nos assuntos mais delicados da alta administração do Estado, constituindo, tal deferência, uma justa e merecida homenagem que the prestavam JÚLIO DE CASTILHOS B BORGES DE MEDEIROS, amigos seus, que o tinham no mais elevado conceito.

A Faculdade de Direito de Porto Alegre nasceu sob a égide do Poder Judiciário, tendo sido decisiva a colaboração do Desembargado JAMES FRANCO, Presidente do Superior Trido discurso que proferiu na sessão de 13 de nho, Sr. Presidente, a esta tribuna, para a qual

bunal de Justiça desde 1894, que franqueou a sua sala de atividade funcional para os contatos com as personalidades do mundo jurídico no Estado, com os quais o ilustre Desembargador THOMPSON FLORES aflorara a iniciativa da instituição da novel Faculdade de Direito, em autêntica ação coordenadora dos esforços em prol desse desiderato.

Impende reconhecer-se, também, a cooperação inestimável dos Doutores JÚLIO DE CASTILHOS E ANTONIO AUGUSTOBORGES DE MEDEIROS ao animar a iniciativa do Desembargador THOMPSON FLORES, inclusive no auxílio material, ao ceder as salas da Escola Normal do Estado para que ali se pudessem realizar as reuniões mais numerosas, onde se verificaram os debates para a criação do novo instituto superior do ensino.

Esse aspecto foi realçado pelo neto do nosso homenageado, o eminente Ministro CARLOS THOMPSONFLORES, ex-Presidente do Supremo Tribunal Federal, em seu discurso proferido no Plenário da Suprema Corte na sessão comemorativa do centenário de PLÍNIO CASADO, verbis:

"De há muito ansiavam os riograndenses pela criação de sua Faculdade de Direito, a exemplo de Recife e São Paulo.

De aguda sensibilidade política, apercebeu-a Júlio de Castilhos.

Dessa missão incumbiu ao então Procurador-Geral Desembargador Carlos Thompson Flores, do Superior Tribunal do Estado, o qual, na busca de valores, inseriu no rol dos mestres, Plínio Casado.

E foi de seus lábios que o Rio Grande ouviu a primeira lição de Direito, na novel Faculdade, aos 4 de maio do ano de 1900 sobre Direito Público e Constitucional." 9

${ }^{8}$ In Anais da Assembléia Legislativa da Província de São Pedro do Sul, Porto Alegre, 1873, Apêndice, II parte, p. 13. ${ }^{9}$ In Discurso do Min. THOMPSON FLORES, in Sessão Comemorativa do Centenário do Nascimento do Ministro PLÍNIO CASADO.

Revista da Faculdade de Direito da UFRGS, v. 20, Outubro/2001 
No mesmo sentido, é o magistério de ANDRÉ BRAGA, em alentado estudo acerca da História da Faculdade de Direito de Porto Alegre, verbis:

"Se a inspiração foi de Júlio de Castilhos que emprestou o máximo apoio à criação da Faculdade e que, segundo alguns, teria mandado - o que era muito do seu feito político, organizar mais este instituto de ensino superior; se amparo moral e material teve de parte do Presidente Borges de Medeiros a mais ampla cobertura; se sob a égide do Tribunal de Justiça do Estado, encontrou a Faculdade na pessoa do Des. James Franco um vibrante estusiasta, animando os colaboradores e presidindo reuniões preparatórias, é imperioso, todavia, que se diga que notável mérito em todos os passos alcançou a personalidade invulgar do Des. Thompson Flores que soube coordenar como líder inconteste o empreendimento, com visivel demonstração de criatividade. Àqueles que de outras gerações perlustraram esta Casa há de se indagar da significação altamente cívica do busto do $1^{\circ}$ Diretor. Desembargador Carlos Thompson Flores, sotoposto na escadaria central, ao pé do vitral Iustitia, a simbolizar a vigilância diuturna, qual sacerdote da justiça, na observância fiel dos princípios doutrinários para fazer do estudante um apóstolo do bem, em mensagem permanente de fé e convicção na aplicação do direito como regramento da conduta humana.

Emergindo do plano judiciário para a política de princípios para a institucionalização do Estado, depois de ter sido Presidente em exercício da Província, legislador constituinte luminar de 91, juiz integro e culto, vai então decidir sobre providências que transcendem o plano das relações individuais na medida em que nelas se envolve um interesse social da comunidade rio-grandense, a exi-

gir-lhe outra forma de reflexão, porque implica na formação humana, estranha à doutrina $e$ ao poder de limitar, mas que exige obviamente a linguagem do senso comum na perquirição das franquias e no respeito à individualidade do mestre e do aluno.

Pela primeira vez, iria coordenar a for mação de uma nova estrutura na tessitura social, a de dar formação jurídica à mocidade conformada aos princípios republicanos. Embora de exuberante inteligência, mas nunca arrebatado, o venerando magistrado exercita proeminente influência política com a fortuna de ser dotado de espírito de concórdia e ponderação, como asseverava a imprensa contemporânea, porque lhe cabia um papel singular na organizaação institucional do Estado e a quem se deve assinalados e relevantíssimos serviços.

Maior distinção entre os seus pares é a de ter sido, portanto, escolhido para dirigir os destinos do terceiro estabelecimento de ensino superior da Capital, a primeira escola de ensino jurídico do Estado, com tanto maior responsabilidade que era consabido ser o instituto indispensável à fixação e aprimoramento das instituições republicanas, ansiosamente esperado pela mocidade rio-grandense afe $i$ ta a uma vida libertária e de convicções políticas definidas." 10

No dia 10 de fevereiro de 1900 acorreram as mais proeminentes personalidades do Estado para ouvir a declaração do Desembargador THOMPSON FLORES, na sala do Atheneu Riograndense, de que estava fundada a Faculdade Livre de Direito de Porto Alegre.

Logo após, em 24 de fevereiro do mesmo ano, na sala de sessões do Superior Tribunal de Justiça do Estado, procedia-se à eleição do primeiro Diretor da Faculdade de Direito, cuja escolha recaiu, por unanimidade de votos, na pessoa do Desembargador CARLOS THOMPSONFLORES

É o que consta da Ata de Instalação e $1^{\mathrm{a}}$ Congregação da Faculdade Livre de Direito de Porto Alegre, verbis:

"Aos vinte e quatro dias do mez de fevereiro de 1900 , reunidos ás duas horas da tarde, na sala de sessões do Superior Tribunal do Estado os Srs. Desembargadores Carlos Thompson Flôres e Epaminondas Brasileiro Ferreira, Dr. Antonio Fausto Neves de Souza, Francisco de Paula Azevedo e Souza, Manoel Pacheco Prates, Timotheo Pereira da Rosa, Antonio Marinho Loureiro Chaves, Leonardo Macedonia Franco e Souza, Marçal Pereira d Escobar, José Joaquim de Andrade Neves Neto Normelio Rosa, Antonio Nunes Gomes Pereira Sebastião Leão, Ricardo Pereira Machado, Joaquim Antonio Ribeiro, Plínio Alvim, Germano Hasslocher, Plínio de Castro Casado, Arthu Pinto da Rocha e James Darcy - foi acclamado Presidente o Dr. Antonio Fausto Neves de Souza o qual declarou achar-se, desde então, installada a Faculdade Livre de Direito de Porto Alegre congratulando-se com os seus collegas presentes por esse magno acontecimento e declarando, em seguida que ia-se proceder á eleição para Director. Esta, por unanimidade de votos, recahiu na pessôa do Sr. Desembargador Carlos Thompson Flôres. O Sr. Director comovidamente agradeceu a investidura que nessa hora recebia dos seus collegas. Passando a funciona a Congregação, sob a presidencia do Director, votou os estatutos, approvando-os como sua lei organica, e de acordo com elles o Sr. Directo escolheu o Desembargador Epaminondas Brasileiro Ferreira para substituil-o, como ViceDirector em seus impedimentos, nomeou Secretario o Dr. James Darcy e Thesoureiro o Dr. Manoel Pacheco Prates. Logo após a Congregação elegeu para constituirem as commissões de Constas: aos Drs. Francisco de Paula Azevedo e Souza, Marçal Pereira de Escobar e Germano Hasslocher; de Revista: os Drs. Sebastião Leão, Plinio de Castro Casado e Arthur Pinto da Rocha; Scientífica: Drs. Timotheo Pereira da Rosa, Plinio Alvim e Joaquim Ribeiro; e ainda para a Comissão de Patrimônio da Faculdade: Drs. Possidonio Mancio da Cunha Junior, José Joaquim de Andrade Neves Neto e Normelio Rosa. O Sr. Director fez sciente á Congregação que convocal-a-ia, mais tarde, para que providenciasse acerca da installação solemne da Faculdade, em dia que seria opportunamente marcado. $\mathrm{E}$ como nada mais houvesse a tratar, o Sr. Director deu por terminados os trabalhos, e encerrada a $1^{\mathrm{a}}$ sessão da Congregação da Faculdade Livre de Direito".

No dia 10 de novembro de 1904, poucos dias antes da colação de grau dos primeiros bacharéis em Direito pela Faculdade de Direito de Porto Alegre, falecia subitamente o Desembargador THOMPSON FLORES, sob a constrangedora tristeza da sociedade de nosso Estado, como atesta o largo noticiário da imprensa da Capital no dia seguinte ao seu sepultamento, o maior daquela época.

Tombava a coluna mestra da Faculdade de Direito, o ilustre e incansável paladino a quem esta Casa do Direito deve a sua existência.

OPresidente do Estado, Dr. BORGES DE MEDEIROS, juntamente com todos os seus auxiliares, o Intendente JOSÉ MONTAURY e os Diretores dos estabelecimentos de ensino superior, além do Presidente da Assembléia Legislativa, Dr. CARLOS BARBOSA, e outras ilustres autoridades, participaram de todos os atos fúnebres, o que estava a demonstrar o apreço e alto conceito que desfrutava Desembargador THOMPSON FLORES perante a sociedade do Rio Grande do Sul.

A personalidade do Desembargador 
THOMPSON FLORES é das que o tempo não pode apagar. Magistrado e homem público íntegro, de dignidade e cultura por todos reconhecida, sua vida, sem qualquer sombra de dúvida, foi a exaltação à liberdade e à inteligência, bem podendo ser seus os versos de SHAKESPEARE dos conjuradores romanos, na peça política Julio Cesar, verbis:

"Ni la tour de pierre, ni les murailles de bronze travaillé, ni le cachot privé d'air, ni les liens de fer massif, ne peuvent enchaîner la force de l'âme; mais la vie fatiguée de ces entraves terrestres ne manque jamais du pouvoir de s'en affranchir". "1

O seu nome serviu de garantia para reunir ao seu redor as melhores inteligências da Ciência do Direito de seu tempo, aglutinados pelo nobre ideal de fundar a Faculdade de Direito de Porto Alegre, marcando com a sua vigorosa personalidade o modelo de estabelecimento de ensino jurídico dos mais notáveis do País.

Em todos os cargos e missões que exerceu, nunca deixou de ser jurista. Mas, para o Desembargador CARLOS THOMPSON FLORES, o papel do jurista jamais se esgotou na esclarecida interpretação e aplicação do Direi to. Ele se completava com a função pedagógica, concorrendo para o aperfeiçoamento humano.

O privilégio de transmitir ensinamentos não só através dos seus votos e acórdãos, mas também no contato direto com os alunos, contribuindo por afeição ao nobre ofício para o aprendizado de várias gerações, evidencia o ideal do saber à serviço da mocidade, quando, num verdadeiro apostolado, repartia com os

${ }^{11}$ In Oeuvres Complètes de Shakespeare, traduction de M. Guizot, neuvième édition, Paris, t. 2, p. 26. ${ }^{12}$ In MARCO FABIO QUINTILIANO, Istituzione Oratoria, traduzione e note di Orazio Frilli, Zanichelli Editore, Bologna, 1984, Libri X-XI-XII, p. 259, I, 25.

${ }^{13}$ In BOSSUET - Oeuvres Choisies, treizième édition, Librairie A. Hatier, Paris, 1941, p. 650.

Revista da Faculdade de Direito da UFRGS, v. 20, Outubro/2001

seus alunos não só a lição do saber jurídico, mas a própria lição da vida, tão enriquecida na sua longa caminhada. Assim, entregava-se ao magistério de espírito e coração. Um mestre, na acepção exata do termo.

Nada mais adequado para destacar a personalidade do Desembargador CARLOS THOMPSON FLORES do que lembrar o conhecido trecho da Institutio Oratoria, de QUINTILIANO, o maior preceptor da Antiguidade e notável Retórico de Roma, quando definiu o seu magistério, emitindo conceitos válidos até o dia de hoje, verbis:

"Infatti noi non diamo una qualunque educazione forense, nè formiamo un mercenario che metta la sua voce in vendita, nè (per addolcire l'espressione) un difensore utile nei processi, che insomma comunemente si chiama causidico, ma un uomo che si elevi per la tempra dell' ingegno e che abbia la mente ricolma di vaste e belle conoscenze, un uomo concesso in dono alla terra, tale quale l'antichità non ne ha mai veduto un eguale, un uomo unico, perfetto in tutto, ammirevole per i suoi sentimenti e per come li esprime". ${ }^{12}$

Vestem-no sem folgas as palavras com que o clérigo de Clérembault, em 02 de junho de 1704, se exprimiu acerca de BOSSUET, por ocasião da morte do célebre pensador francês, verbis:

"Ce grand personnage était un de ces hommes rares et supérieurs qui sont quelquefois au monde pour lui faire seulement sentir jusqu'où peut être porté le mérite sublime, sans laisser presque l'espérance de leur pouvoir trouver des successeurs." 13
Realmente, a vida só se completa com a morte. No entanto, só a morte dá a dimensão integral de uma vida.

O Desembargador THOMPSON FLORES foi um homem e um juiz severo e intransigente no culto do dever, inflexível consigo mesmo. Nunca soube cortejar. Nunca soube pedir. O magistrado, com efeito, não pede jamais. Espoliado ou ameaçado em seu direito, resiste com altivez, exigindo o cumprimento da lei. Mas não pede, não se curva. Ao contrário, sempre soube renunciar às coisas vãs e ilusórias da vida.

No Superior Tribunal do Estado, o insigne jurista ratificou o alto conceito que desfrutava na Província. Permaneceu nesta Corte cerca de treze anos, período suficiente para deixar a marca de sua sólida formação jurídica, revelada no exercício da judicatura, pois sentira, desde o primeiro instante, o desafio cultural e humano que representava a multiplicidade e a complexidade das questões decididas pelo Tri bunal, atento, sempre, à advertência de FRANCIS BACON aos juízes no sentido de que a sua missão constitui "a wise use and application of laws". ${ }^{14}$ Quem reunir os votos que proferiu, notadamente no terreno do Direito Privado, terá uma antologia de lições esplêndidas.

Um exemplo basta para atestar a verdade da asserção. Modelo de síntese e precisão, esta passagem do voto que emitiu no julgamento da apelação cível n ${ }^{\circ} 204$, versando causa de anulação de casamento por motivo de coação, verbis:

"O Juiz a quo julgou dar-se o caso previsto e arguido no procedimento do juiz districtal que presidiu o casamento, tendo

${ }^{14}$ In The Essays, Penguin Books, 1985, p. 225

${ }^{15}$ In Decisões do Superior Tribunal - ano 1896, p. 257

Revista da Faculdade de Direito da UFRGS, v. 20, Outubro/200 colligido da instrucção feita ameaça de processo por crime de defloramento, dando causa ao consentimento do autor Marcellino Brum n'esse acto.

Considerando, porém, que tal apreciação é desacertada, ainda não attendida a duvida da prova que devêra ser " muito plena e liquidissima" em vista do theor do instrumento da celebração do casamento, e da não se tratando da falta de consentimento quimavult, vult, $e$ sim de determinado vicio d'elle, o mesmo, a coacção, não se entende existir na hypothese, qual a devida intervenção da autoridade com competencia tutelar sobre a miseravel offendida, para o fim da reparação legal (art. 276, § único, do Codigo Penal), que se operou; Considerando que nem a voz de prisão, circumstancia allegada, está sufficientemente verificada, como qualquer mal, ou perigo "consideravel e presente" a poder amedrontar irresistivelmente o autor apellado para a sua determinação de csar-se; não sendo elle pessoa rustica a ponto de desconhcer as garantias legaes, nem de animo tão timido, como por sua parte se inculca, attenta a qualificação resultante dos autos; $e$ sob similhantes respeitos deve ser consultada a doutrina e bem assim a legislação comparada (Pothier, "Obrigações", ann. Corrêa Telles, Part $1^{a}$, numeros 21 a 26; Rogrou aos artigos 1.111 a 1.112, "Cod. Napol"; Giarelli - ao art. 1.112, Cod. Civil Ital.; Dias Ferreira - ao art 663, "Cod. Civ. Port."; e Coelho da Rocha, "Dir. Civ." \$\$ 102 e 736)". 15

Problemas de Direito Público iriam ocupar, por largo tempo, a atenção de THOMPSON FLORES. Num momento em que as obras fundamentais nessa especialidade ainda não haviam sido dadas à lume, o estudo da matéria consconveniencia da solidez d'este acto, - pois que, 
titucional conduzia, inevitavelmente, à análise da doutrina estrangeira, trabalho que o eminente magistrado levou a termo com lucidez e prudência.

Exemplo disto está na posição por ele assumida relativamente ao cuidado e à cautela do Juiz ao reconhecer a insconstitucionalidade das leis, a evidenciar insuspeitados conhecimentos do direito constitucional americano, verbis:

"Considerando que a attribuição, ou funcção jurisdiccional, objecto da excepção n'este processo, é por sua natureza restricta, devendo ser attendida nos termos rigorosos da declaração legal (art. $8^{\circ}$ da Cit. L. n. 10, $v b$. manifestamente), e de accôrdo com a doutrina, calcada sobre a jurisprudencia do systhema constitucional americano, que adverte ao juiz que a constitucionalidade da lei é presumida, que só cumpre-lhe declarar um acto inconstitucional, quando elle clara e evidentemente viola a Constituição, devendo, em caso de duvida, ser em favor do Poder Legislativo, e que o assumpto é extremamente delicado, é para ser tratado com reluctancia e hesitação para não subverter-se a necessaria e legitima co-ordenação dos departamentos do poder publico, e não se desprestigiar o regimen republicano, que deve ser verdadeiramente o governo da lei. (Tim. Walker, Introd. To American Law. Part. $2^{a}$ Secç. 27, pg. 73, not. B; Cooley, Const. Limit., cap. $7^{\circ}$, pgs. 193, 195 e 216)." 16

Outro caso a merecer destaque foi a questão da competência da Justiça do Estado para o julgamento de ação de indenização ajuizada contra empresa estrangeira, tópico raramente versado em nosso direito naquela época, verbis:

${ }^{16}$ In Op. Cit., p. 30

${ }^{17}$ In Op. Cit., p. 105

Revista da Faculdade de Direito da UFRGS, v. 20, Outubro/2001 “a) A qualidade allegada de ser extrangeira a Ré, attenta a natureza da acção para pagamento de divida de serviços, restituição de retenções de quantias, e indemnisação de prejuizos, perdas e damnos, tudo decorrente de actos administrativos da mesma companhia, excipiente, não limita a jurisdicção comum local em virtude do nosso regimen constitucional federativo mais liberal do que o das constituições norte-americana e argentina, perante o qual por esse motivo a especie seria da competencia da justiça federal;

b) A acção não interessa ao Fisco $\mathrm{Na}$ cional, não perdendo a Ré pelo facto do privilegio e garantia de juros não tendo na hypothese o Fisco a minima intervenção, quer como assistente, que como oppoente, como bem se conhece da informação prestada pelo engenheiro representante daquelle Governo, ut a fl. 99. Condemnão a aggravante nas custas." 17

Esse registro, como um perfil, contém apenas alguns índices representativos da escala de sua atividade judicante, impossível de se condensar, nesta oportunidade, quer pelo número das manifestações, quer pela diversidade das proposições.

Impressionava, sobremaneira, o que dele diziam os seus contemporâneos, não só os seus eminentes Colegas do Superior Tribunal do Estado, como todos aqueles que o conheceram e privaram de seu convívio humano e acolhedor, da integridade do seu caráter.

Parafraseando MACHADO DE ASSIS, os qualificativos estão já tão gastos que dizer que um homem é virtuoso, parece que não é dizer nada. Mas, em realidade, quantos merecem rigorosamente esta qualificação tão simples e tão curta? $O$ grande assombra, o glorioso ilumina, o intrépido arrebata; o virtuoso não produz nenhum desses efeitos. Contudo, em sua ação e no seu modo de proceder há uma grandeza, há uma glória, há uma intrepidez em ser simplesmente virtuoso, sem aparato, nem interesse, nem cálculo.

\section{Virtus est omnium bonorum maximum}

O conhecido historiador romano SAUSTIO escreveu, em certa oportunidade, que "l'éclat de la richesse et de la beauté est fragile et passager, la vertu seule demeure glorieuse et immortelle". ${ }^{18}$

Poderia falar, ainda, muito mais, de senvolvendo cada parágrafo do que acabo de dizer, referindo-me às diversas fases da vida e às múltiplas atividades do talentoso jurista que foi o Desembargador CARLOS THOMPSON FLORES

Creio, porém, que basta. Repetindo RENAN, os fatos consumados dizem mais do que todas as individuações biográficas.

Em um de seus famosos Diálogos De Brevitate Vitae -, SÊNECA exproba o brocardo "vitam brevem esse, longam artem". Na sua concepção, a vida nos proporciona tempo de sobejo, nós é que o perdemos demasiado ("nous n'avons pas peu de temps, nous en avons beaucoup de perdu"). ${ }^{19}$ Desconheço se o Desembargador CARLOS THOMPSON FLORES, em algum momento de sua vida, teria lido essas páginas do filósofo romano. Se não as leu, seguiu-as, contudo, por intuição. Viveu como bom ecônomo do tempo. Por ocasião do seu falecimento, após mais de quarenta anos de magníficos serviços prestados ao seu país, e toda uma existência votada ao magistério e às letras jurídicas, aureolado pelo prestígio e admiração que soube granjear de toda a sociedade de sua época, CARLOS THOMPSON FLORES deixou para os pósteros o exemplo de uma vida de progressão contínua, mercê de trabalho incansável, legando a seus descendentes um nome respeitado e venerado, por suas virtudes cívicas e privadas.

${ }^{18}$ In SALLUSTE, Conjuration de Catilina, texte établi par B. Ornstein et traduit par J. Roman, Société d'édition "Les Belles Lettres", Paris, 1924, p. 1.

${ }^{19}$ In SÉNÈQUE, Dialogues, texte établi et traduit par A. Bourgery, Société d'édition "Les Belles Lettres", Paris, 1923 , t. II, pp. $47 / 8$. 